\title{
Pancreatic fat deposition is increased and related to beta-cell function in women with familial partial lipodystrophy
}

\author{
Amelio F. Godoy-Matos ${ }^{1 *}$, Cynthia M. Valerio ${ }^{1}$, Rodrigo O. Moreira ${ }^{1}$, Denise P. Momesso ${ }^{1}$ \\ and Leonardo K. Bittencourt ${ }^{2}$
}

\begin{abstract}
Background: To study pancreatic fat deposition and beta-cell function in familial partial lipodystrophy (FPLD) patients.

Methods: In a cross-sectional study, eleven patients with FPLD, and eight healthy volunteers were matched for age and body mass index and studied at a referral center. Body composition was assessed using dual-energy X-ray absorptiometry and the Dixon method of magnetic resonance imaging was used to quantify pancreatic and liver fat. Fasting plasma glucose, insulin, leptin, lipids and homeostasis model assessment of insulin resistance values were measured, and an oral glucose tolerance test was performed. The insulinogenic index, Matsuda insulin sensitivity index and betacell disposition index were calculated.

Results: The FPLD group presented a higher waist-to-hip ratio and fat mass ratio and lower total, truncal and lower-limb fat masses. Pancreatic and liver fat contents (log transformed) were significantly higher in the FPLD group ( $5.26 \pm 1.5$ vs. $4.08 \pm 0.64, p=0.034$ and $0.77 \pm 0.50$ vs. $0.41 \pm 0.18, p=0.056$, respectively). Pancreatic fat was inversely related to the $\mathrm{DI}(r=-0.53, p=0.027)$ and $\mathrm{HDL}$-cholesterol $(r=-0.63, p=0.003)$ and directly related to WHR $(r=0.60 ; p=0.009), \operatorname{HbA1c}(r=0.58 ; p=0.01)$ and serum triglyceride $(r=0.48, p=0.034)$. Higher triglyceride and lower HDL-cholesterol levels were observed in the FPLD group.

Conclusions: This study demonstrated for the first time that pancreatic fat deposition is increased in FPLD. Moreover, an inverse relationship was demonstrated between pancreatic fat and beta-cell function. The findings of this study may be consistent with the expandability hypothesis and the twin cycle hypothesis.
\end{abstract}

Keywords: Lipodystrophy, Pancreas, Ectopic fat, Beta cell function

\section{Background}

Lipodystrophies (LP) are a clinically heterogeneous group of genetic or acquired disorders characterized by a variable loss of subcutaneous adipose tissue [1]. Familial partial lipodystrophy (FPLD), which is currently the most common and well-described familial LP, is characterized by reduced subcutaneous (SC) fat deposition affecting the limbs and trunk, with a selective visceral

\footnotetext{
*Correspondence: agodoymatos@gmail.com

1 Serviço de Metabologia, Instituto Estadual de Diabetes e Endocrinologia (IEDE), Rua Visconde Silva, 52/1135 Botafogo, Rio de Janeiro 22271-090, Brazil

Full list of author information is available at the end of the article
}

lipodeposition and SC fat accumulation in the shoulder girdle, neck and face. FPLD patients exhibit marked insulin resistance with glucose intolerance or diabetes mellitus (DM), dyslipidemia, acanthosis nigricans and a high risk of cardiovascular (CV) disease [2-4]. The phenotype of FPLD most resembles the metabolic syndrome phenotype observed in the general population [4]. Therefore, a better understanding of this underexplored pathology can reveal important clues to decipher insulin resistance (IR) and its metabolic consequences.

Visceral adiposity and ectopic fat accumulations have been associated with FPLD [5-7]. These ectopic fat depositions might be related to organ dysfunction and adverse 
cardiometabolic effects. Our group described increased epicardial adipose tissue in a cohort of FPLD patients assessed by echocardiography [8]. Lipid accumulations in the liver and muscles were observed in mouse models of inherited LP [9]. Currently, an area of special interest is the possibility of pancreatic fat deposition in FPLD patients, a human model of insulin resistance $[9,10]$. Chronic exposure of the pancreatic islets to non-esterified fatty acids is considered a potential primary cause of beta-cell dysfunction [10]. Indeed, recent evidence suggests that pancreatic lipid content may contribute to beta-cell dysfunction and possibly to the subsequent development of type 2 diabetes in susceptible individuals [11].

The most accurate measurements of body fat deposits are obtained using radiologic methods, namely, dualenergy X-ray absorptiometry (DXA) and magnetic resonance imaging (MRI), and techniques such as proton spectroscopy (H-MRS) and Dixon-based fat quantification (MRI-DIXON), especially for the determination of hepatic and pancreatic fat content [12-15]. These techniques have been validated against the direct determination of triglyceride content in human liver biopsies.

Currently, to the best of our knowledge, no data are available on the evaluation of fat deposition in the pancreas of FPLD patients. Furthermore, the relationship between pancreatic and hepatic fat deposition and betacell function has not been well studied. The aims of this study were to evaluate pancreatic and hepatic fat content and their correlation with beta-cell function in FPLD patients.

\section{Methods}

\section{Subjects}

Eleven women with FPLD from the outpatient clinics of Serviço de Metabologia do Instituto Estadual de Diabetes e Endocrinologia do Rio de Janeiro (Rio de Janeiro, Brazil) were included. The diagnosis of FPLD was confirmed by the molecular analysis of the LMNA gene (ABI Prism 3100 Genetic Analyzer; Applied Biosystems, Foster City, CA, USA) performed by the Molecular Endocrinology Laboratory of Paulista Medical School. Eleven patients had a missense mutation in the LMNA gene: seven patients harbored the heterozygous variant p.R482W (c.1444C $>\mathrm{T}$ ), in three patients, the mutation identified was p.R482Q (c.1445G>A), and one patient exhibited a novel heterozygous variant in exon 8 (p.N466D $(c .1396 \mathrm{~A}>\mathrm{G})$ described previously [7]. The patients belonged to six different families.

A control group of 8 healthy women was carefully and sequentially selected to match the lipodystrophic group according to body mass index (BMI) and age. All controls were healthy and had no previous medical conditions likely to influence the evaluation at the time of the study.

The exclusion criteria were as follows: pregnant or breast-feeding women; severe renal or hepatic diseases; depression or alcoholism; use of thiazolidinediones (TZD) in the last 6 months or current use of glucocorticoids; and recent significant weight loss $(\geq 3 \mathrm{~kg}$ in the last 3 months).

The study protocol was approved by the local ethics committee.

\section{Anthropometrical examination}

The following anthropometrical data were recorded in all participants: body weight $(\mathrm{kg})$, height $(\mathrm{m})$, waist circumference $(\mathrm{cm})$, waist-to-hip ratio (WHR), and blood pressure $(\mathrm{mmHg})$. The BMI was calculated as weight in kilograms divided by the square of height in meters $(\mathrm{kg} /$ $\mathrm{m}^{2}$ ). The waist circumference was determined at the midpoint between the lowest rib and the iliac crest. The WHR was defined as the ratio of waist girth to the largest circumference of the hips, measured at the greater trochanter.

\section{Laboratory evaluation Biochemical analyses}

Blood samples were collected between 06:30 and 08:00 a.m. after an overnight fast (12 h). Plasma glucose was determined using the glucose-oxidase method. The cholesterol content of the lipoprotein fractions and triglycerides were measured enzymatically. Plasma leptin and insulin concentrations were measured using a radioimmunoassay. Fasting, 30, 60 and 120 min post load glucose levels were determined after a 75 -g oral glucose tolerance test (OGTT).

\section{Beta-cell function parameters}

IR was estimated using the homeostasis model assessment (HOMA-IR) using the following formula: $I R=$ fasting insulin $\times$ fasting glucose/22.5. The insulinogenic index (II) was calculated as the increment of insulin above the fasting level at $30 \mathrm{~min}$ divided by the corresponding glucose increment [16]. Since insulin secretion is dependent on insulin sensitivity, we evaluated the betacell disposition index (DI), calculated as the product of the II and the Matsuda index of insulin sensitivity (II $\times 1$ / insulin) $[17,18]$.

\section{Body fat analysis using DXA}

A DXA scan (LUNAR PRODIGY ADVANCE software, version 9.5, LNR 41569 model; GE Medical Systems, Waukesha, WI, USA) was performed. The fat quantity and distribution were analyzed using the following variables: total fat (\%), trunk fat (\%), upper and lower limb fat 
(\%), fat mass (g), central fat (g), and peripheral fat (g). The central-to-peripheral fat ratio or the fat mass ratio (FMR) was used to investigate body fat distribution, as previously described $[5,6,19]$.

\section{Pancreas and liver fat deposition evaluated by MRI-DIXON}

Subjects underwent imaging examinations of the liver and pancreas in the supine position via a 1.5 T Magnetom Avanto MR unit (Siemens Healthineers, Erlangen, Germany). After positioning the abdomen in a phased array coil, axial images were acquired from the level of the liver and pancreas using the two-point Dixon sequence as part of the routine clinical MRI protocol of the upper abdomen (not included for analysis in this study). The entire procedure, including positioning and scanning, was completed within $20 \mathrm{~min}$. After completion of the automated reconstruction of the two-point Dixon images, the image sets of "fat only" and "water only" maps were transferred to a picture archiving and communication system (Carestream, Haifa, Israel) for analysis. The signal intensities in the images were calculated with operator-defined regions of interest (ROIs) at the same location in both fat and water images. A total of three ROIs per organ (liver and pancreas) were measured and averaged by a single investigator with care given to the placement of the ROIs to avoid confounding anatomy (e.g., large blood vessels). Fat/water ratios were calculated on a pixel-by-pixel basis by dividing the signal intensity calculated from the fat image by the signal intensity calculated from the water image $(\mathrm{FF} \%=[\mathrm{F}] /[\mathrm{W}+\mathrm{F}])$. Decomposing fat and water signals to discriminate between fat and water protons based on their resonant frequency difference was first introduced by Dixon [15]. This method uses two acquisitions with a delay between the radiofrequency (RF) and gradient echoes such that the phase shift between the water and fat is either 0 or $90^{\circ}$ (in-phase and out-ofphase, respectively). Separate water and fat images can be obtained by adding and subtracting the in-phase and outof-phase images. The pulse sequence parameters were as follows: TR/TE in-phase 7.5/4.8 ms, TR/TE out-of-phase $7.5 / 2.4 \mathrm{~ms}$, slice thickness $3 \mathrm{~mm}$, matrix $=320 \times 166$, $\mathrm{NEX}=1$, and total scan time $=20 \mathrm{~s}$.

\section{Statistical analysis}

Statistical analysis was performed using GraphPad InStat 3.00 for Windows 95 (GraphPad So ware, San Diego, CA, USA). Parametric data are shown as mean \pm standard deviation and non-parametric, such as median (range). An unpaired $t$-test was used to compare parametric variables, and the Mann-Whitney test or unpaired t-test (Welch corrected) were used for non-parametric variables. The strength of the linear relationship between two continuous variables was evaluated using Pearson or Spearman's Coefficient. The level of statistical significance was $5 \%$. Logarithmic-transformed values were used only for the liver fat variable due to the great dispersion of values.

\section{Results}

Eleven women with FPLD were evaluated in our study. Ten patients were diagnosed with type $2 \mathrm{DM}$ and were taking metformin, and one had impaired fasting glucose. The duration of diabetes varied from 1 to 10 years. Patients belonged to 6 different families as described in previous reports [5-7]. Table 1 describes baseline characteristics of the study population. The FPLD and control groups did not differ significantly with respect to age, BMI and waist circumference. As expected, the FPLD group presented a higher WHR and FMR and lower total, truncal and limb fat masses. The biochemical variables included higher triglycerides and lower HDL-cholesterol levels. Leptin was remarkably lower in the FPLD (4.2,

Table 1 Anthropometrical examination, body fat analysis by DXA, pancreas and liver fat content by MRI-DIXON and biochemical variables in women with familial partial lipodystrophy (FPLD) and control groups

\begin{tabular}{lllc}
\hline & Control $(\mathbf{n}=\mathbf{8})$ & FPLD $(\mathbf{n}=\mathbf{1 1})$ & $\mathbf{p}$ \\
\hline Age (years) & $32.3(28.2-59.6)$ & $33.0(19.4-53.8)$ & 0.65 \\
BMl (kg/m $\left.{ }^{2}\right)$ & $24.4 \pm 2.8$ & $23.3 \pm 3.4$ & 0.43 \\
Waist (cm) & $80.3 \pm 4.3$ & $81.3 \pm 8.6$ & 0.77 \\
Hip (cm) & $100.1 \pm 6.9$ & $88.2 \pm 4.6$ & $<0.001$ \\
WHR & $0.80 \pm 0.04$ & $0.92 \pm 0.07$ & 0.001 \\
Total fat (\%) & $38.1(32.8-46.2)$ & $16.2(13.1-27.6)$ & $<0.01$ \\
Trunk fat ${ }^{\mathrm{a}}(\%)$ & $38.6(31.5-47.3)$ & $20.9(16.3-34.6)$ & 0.0018 \\
Limbs fat $^{\mathrm{a}}(\%)$ & $44.1 \pm 4.4$ & $13.2 \pm 4.4$ & $<0.001$ \\
FMR & $0.89 \pm 0.06$ & $1.85 \pm 0.40$ & $<0.001$ \\
Pancreas fat ${ }^{\mathrm{b}}(\%)$ & $4.08 \pm 0.64$ & $5.26 \pm 1.5$ & 0.034 \\
Liver fat ${ }^{\mathrm{b}}$ (log) & $0.41 \pm 0.18$ & $0.77 \pm 0.50$ & 0.056 \\
Leptin (ng/ml) & $19.2(11.5-27.4)$ & $4.2(2.4-29.0)$ & 0.028 \\
Glucose (mg/dl) & $81.5(73.0-94.0)$ & $102.0(76.0-168.0)$ & 0.025 \\
HbA1c (\%) & $5.05 \pm 0.41$ & $6.20 \pm 0.92$ & 0.007 \\
AST & $17.5(12.0-28.0)$ & $18.0(13.0-69.0)$ & 0.77 \\
ALT & $15.0(9.0-29.0)$ & $22.0(9.0-115.0)$ & 0.14 \\
Total Cholesterol (mg/dl) & $196.5 \pm 40.3$ & $191.5 \pm 26.9$ & 0.75 \\
HDL-c (mg/dl) & $60.8 \pm 11.3$ & $40.5 \pm 6.8$ & $<0.001$ \\
TG (mg/dl) & $116(47-160)$ & $203(103-392)$ & 0.01 \\
Disposition index & $0.24(0.13-2.07)$ & $0.08(0.01-0.17)$ & $<0.001$ \\
\hline
\end{tabular}

Data are mean $\pm S D$ or median (interval)

FPLD familial partial lipodystrophy, $B M I$ body mass index, $H b A 1 \mathrm{c}$ hemoglobin A1c, WHR waist-to-hip ratio, FMR fat mass ratio (trunk/limbs fat), $H D L$ high density lipoprotein, $T G$ triglycerides, $D /$ disposition index, $M R I$ magnetic resonance imaging

a Body fat estimated from dual energy X-ray absorptiometry

b Pancreas and liver fat measured by MRI Dixon method 
$2.4-29.0 \mathrm{ng} / \mathrm{ml})$ than in the control group (19.2, 11.5$27.4 \mathrm{ng} / \mathrm{ml}, \mathrm{p}=0.028)$.

The main finding in this study was that the pancreatic fat content was significantly higher in the FPLD group than that in the control group $(5.26 \pm 1.50$ vs. $4.08 \pm 0.64$, $\mathrm{p}=0.034)$. In addition, the DI was significantly lower in the FPLD group [0.08 $(0.01-0.17)$ vs $0.24(0.13-2.07)$ $\mathrm{p}<0.001]$. Importantly, the pancreatic fat content was inversely related to the DI $(\mathrm{r}=-0.53, \mathrm{p}=0.027$; Fig. 1$)$ and HDL-cholesterol level $(\mathrm{r}=-0.63, \mathrm{p}=0.003)$ and directly related to WHR $(r=0.60 ; p=0.009)$, HbA1c $(\mathrm{r}=0.58 ; \mathrm{p}=0.01)$ and serum triglyceride $(\mathrm{r}=0.48$, $\mathrm{p}=0.034)$. No correlation was found between pancreatic fat content and waist $(r=0.19 ; \mathrm{p}=0.43)$, total cholesterol $(\mathrm{r}=0.21 ; \mathrm{p}=0.36)$, AST $(\mathrm{r}=0.29 ; \mathrm{p}=0.21)$ or ALT $(\mathrm{r}=0.42 ; \mathrm{p}=0.07)$.

Considering the great dispersion of values (ranging from 37.3 to $1.6 \%$ ), log-transformed values were used to analyze the liver fat percentage. Liver fat was also increased in the FPLD group $(0.77 \pm 0.50$ vs. $0.41 \pm 0.18$, $\mathrm{p}=0.056)$.

\section{Discussion}

For the first time in the literature, the current results show that patients with FPLD, have increased pancreatic fat as measured using the MRI-DIXON method. Similarly, in these patients, the pancreatic fat was inversely correlated with beta-cell function, suggesting that the mechanisms of beta-cell failure and diabetes may be associated with lipotoxicity [10-12].

As previously described, non-alcoholic fatty liver disease (NAFLD) is a commonly associated feature

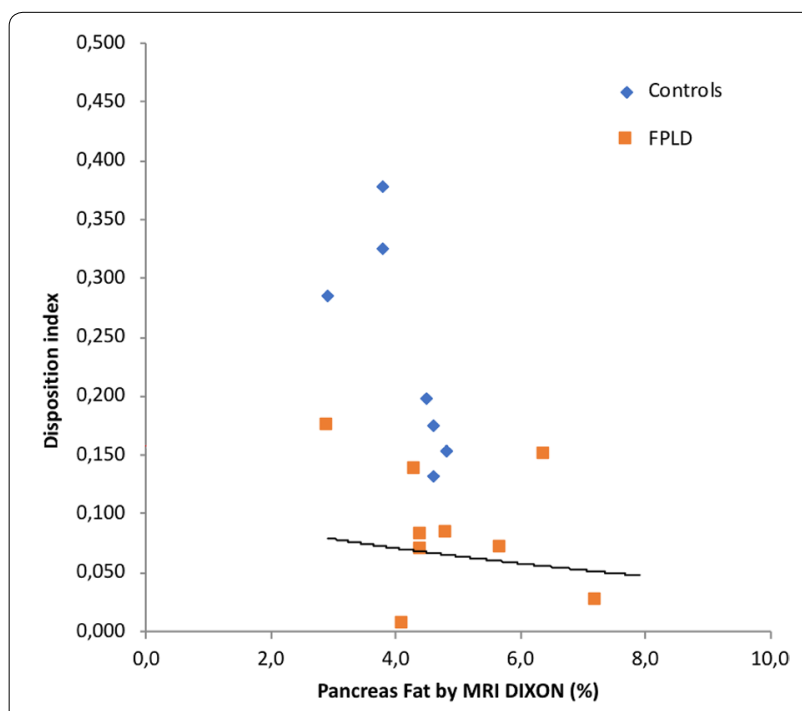

Fig. 1 Correlation between disposition index (DI) and pancreatic fat measured by DIXON method $(r=-0.53, p=0.027)$ observed with IR in FPLD patients [1-4]. In our registry, liver fat was increased in 8 of 11 patients of the FPLD group. Although the log-transformed values were used for statistical analysis, the median fat percentage was $11.7 \%$, which was similar to the findings of a cohort of 23 FPLD patients recently described by Ajnuli et al. [20] $(11.9 \pm 6.3 \%)$.

Liver and pancreatic fat deposition is consistent with the "twin cycle hypothesis", which suggests that progressive liver and pancreatic fat accumulation will lead to a self-reinforcing cycle resulting in beta-cell dysfunction [21]. Interestingly, Lim et al. [22] demonstrated that after 8 weeks of a very low-calorie diet, the reversal of type 2 diabetes and complete beta-cell function recovery were temporarily coincident with a marked reduction in liver and pancreatic fat.

The expandability hypothesis suggests that a relative incapacity of adipose tissue to expand, and therefore store lipids, would cause excess fat to be stored in nonadipose tissues such as the liver and muscle, causing IR and lipotoxicity [23]. Peripheral fat scarcity (i.e., leg fat) is a hallmark of partial lipodystrophy $[1,2,4]$. In a previous report, Ajnuli et al. [20] showed that lower leg fat mass was correlated with higher triglycerides in FLPD patients, suggesting a pathogenic link between higher triglyceride levels and the incapacity to deposit fat in the lower leg. Similarly, these authors found an FMR above 1.5 in a cohort of 23 adult females with FPLD, a finding that was similar to ours (FMR $=1.85$ in the FPLD group). Thus, lower leg fat mass may be the main reason why excess ingested energy accumulates in ectopic tissues, including the pancreas, therefore leading to metabolic impairment.

Normal weight metabolically unhealthy (NWMU) people have recently been characterized by genetic, anthropometric and body composition methods [24-27]. These studies highlight that common genetic variants associated with indices of IR or fat distribution are associated with metabolic features [25] and lower adiposity and BMI $[24,27]$, such as that found in monogenic lipodystrophies [1, 20, 28]. In addition, Stefan et al. [26] studied a cohort of 981 subjects who were at risk for metabolic diseases using whole-body MRI. Among the normalweight subjects, $\sim 20 \%$ were NWMU individuals who exhibited a high prevalence of low percentage of SC leg fat mass. When NWMU subjects were compared to metabolically unhealthy overweight or obese subjects, a gradual increase in the prevalence of low leg fat mass was found $(\beta=0.99, p<0.0001)$, while a stronger increase was observed in the prevalence of NAFLD $(\beta=1.21$, $\mathrm{p}<0.0001)$ [26]. Taken together, this suggests a lipodystrophic-like phenotype.

Some limitations of this study must be acknowledged. We performed pancreatic fat quantification using 
Dixon method. The fatty infiltration of pancreas is increased during the fifth to seventh decade, therefore the use of this non-invasive technique in a younger and age-matched population may lead to a more accurate quantification $[11,12]$.

Additionally, most of our patients were already diagnosed with diabetes and one was glucose intolerant. In this study the gold-standard method to investigate beta-cell function, the hyperglycemic clamp method, was substituted by OGTT, which is widely used as well in literature and provides valuable information of "residual" beta-cell function $[11,17,18]$. According to the results obtained, we were able to confirm that the typical insulin resistant state observed in the FPLD patient is related to increased pancreatic fat content, when compared to controls, independent of aging or BMI.

This study is crucial to understanding this model of human IR and type 2 diabetes risk. It is consistent with an integrative genetic analysis of 53 genomic loci that reported that peripheral fat scarcity, and therefore limited fat storage capacity, is implicated in IR, diabetes and $\mathrm{CV}$ risk [27]. Indeed, in a recent Mendelian randomization study, a polygenic risk score of 48 SNPs for increased WHR (adjusted for BMI) provided causal evidence of the association with a higher risk for diabetes and coronary heart disease [29]. Notably, for each 1 -SD genetic increase in WHR adjusted for BMI, an OR increment of 1.77 [95\% CI 1.57-2.00] and of 1.46 [95\% CI 1.32-1.62] for diabetes and CHD, respectively, was found.

In conclusion, this study demonstrated a unique feature of FPLD, specifically, an increase in pancreatic fat deposition as well as its inverse correlation with beta-cell function. Together with its typical peripheral fat scarcity, this model of IR diabetes is consistent with new evidence linking common genetic variants to a frequent lipodystrophic-like phenotype of lower leg fat mass, ectopic fat deposition, diabetes and CV risk. The findings of this study may be consistent with the expandability hypothesis and the twin cycle hypothesis.

\begin{abstract}
Abbreviations
LP: lipodystrophy; FPLD: familial partial lipodystrophy; IR: insulin resistance; NAFLD: non-alcoholic fatty liver disease; CV: cardiovascular; WHR: waist-tohip ratio; DXA: dual-energy X-ray absorptiometry; MRI: magnetic resonance imaging and techniques; MRI-DIXON: Dixon-based fat quantification; BMI: body mass index; OGTT: oral glucose tolerance test; II: insulinogenic index; DI: beta-cell disposition index; FMR: fat mass ratio; NWMU: normal weight metabolically unhealthy.
\end{abstract}

\section{Authors' contributions}

AFG-M: study design, literature review, figures, data collection, data interpretation and writing. CMV, ROM, DM: data collection, interpretation and writing. ROM: data analysis and statistics. LKB: image acquisition, data collection, interpretation and writing. All authors read and approved the final manuscript.

\section{Author details}

${ }^{1}$ Serviço de Metabologia, Instituto Estadual de Diabetes e Endocrinologia (IEDE), Rua Visconde Silva, 52/1135 Botafogo, Rio de Janeiro 22271-090, Brazil. ${ }^{2}$ Departamento de Radiologia, Universidade Federal Fluminense-Section Head, Abdominal and Pelvic Imaging-CDPI Clinics, DASA Company, Rio de Janeiro, Brazil.

\section{Acknowledgements}

Not applicable.

\section{Competing interests}

The authors declare that they have no competing interests.

\section{Consent for publication}

Not applicable.

\section{Ethics approval and consent to participate}

All subjects were required to give their written informed consent. The Ethics Committee of the Institutional Review Board of State Institute of Diabetes and Endocrinology (IEDE), approved this study.

\section{Funding}

No funding was received for this study.

\section{Publisher's Note}

Springer Nature remains neutral with regard to jurisdictional claims in published maps and institutional affiliations.

Received: 27 July 2018 Accepted: 24 September 2018

Published online: 26 September 2018

References

1. Garg A. Lipodystrophies: genetic and acquired body fat disorders. J Clin Endocrinol Metab. 2011;96:3313-25.

2. Garg A, Peshock R, Fleckenstein J. Adipose tissue distribution pattern in patients with familial partial lipodystrophy (Dunnigan variety). J Clin Endocrinol Metab. 1999:84:170-4.

3. Capeau J, Magré J, Lascols O, et al. Diseases of adipose tissue: genetic and acquired lipodystrophies. Biochem Soc Trans. 2005;33:1073-7.

4. Brown RJ, Committee Chair, Araujo-Vilar D, et al. The diagnosis and management of lipodystrophy syndromes: a multi-society practice guideline. J Clin Endocrinol Metab. 2016;101:4500-11.

5. Valerio CM, Zajdenverg L, Oliveira JEP, Mory PB, Moyses RS, GodoyMatos AF. Body composition study by dual-energy X-ray absorptiometry in familial partial lipodystrophy: finding new tools for an objective evaluation. Diabetol Metab Syndr. 2015;7:19.

6. Godoy-Matos AF, Moreira RO, Valerio CM, Mory PB, Moises RS. A new method for body fat evaluation, body adiposity index, is useful in women with familial partial lipodystrophy. Obesity. 2012;20:440-3.

7. Mory PB, Crispim F, Freire MB, Salles JE, Valério CM, Godoy-Matos AF, Dib SA, Moisés RS. Phenotipic diversity in patients with lipodystrophy associated with LMNA mutations. Eur J Endocrinol. 2012;167:423-31.

8. Godoy-Matos AF, Valério CM, Bragança JB, Oliveira Rde A, Zagury RL, de Paula Lustosa R, Camargo GC, Nascimento CA, Moreira RO. Evaluation of epicardial adipose tissue in familial partial lipodystrophy. Diabetol Metab Syndr. 2015;7:29.

9. Savage DB. Mouse models of inherited lipodystrophy. Dis Model Mech. 2009;2:554-62

10. Shimabukuro M, Zhou YT, Levi M, Unger RH. Fatty acid-induced beta cell apoptosis: a link between obesity and diabetes. Proc Natl Acad Sci USA. 1998;95:2498-502.

11. Tushuizen ME, Bunck MC, Pouwels PJ, Bontemps S, van Waesberghe $J H$, Schindhelm RK, Mari A, Heine RJ, Diamant M. Pancreatic fat content and beta cell function in men with and without type 2 diabetes. Diabetes Care. 2007;11:2916-21.

12. Lingvay I, Esser V, Legendre JL, Price AL, Werts KM, Adams-Huet B, Zhang $\mathrm{S}$, Unger RH, Szczepaniak LS. Noninvasive quantification of pancreatic fat in humans. J Clin Endocrinol Metab. 2009;94:4070-6. 
13. Longo R, Pollescello P, Ricci C, Massutti F, Kvam BJ, Bercich L, Croce LS, Grigo-lato P, Paoletti S, De Bernard B. Proton MR spectroscopy in quantitative in vivo determination of fat content in human liver steatosis. J Magn Reson Imaging. 1995;5:281-5.

14. Szczepaniak LS, Nurenberg P, Leonard D, Browning JD, Reingold JS, Grundy S, Hobbs JJ, Dobbins RL. Magnetic resonance spectroscopy to measure hepatic triglyceride content: prevalence of hepatic steatosis in the general population. Am J Physiol Endocrinol Metab. 2005;288:E462-8.

15. Dixon W. Simple proton spectroscopic imaging. Radiology. 1984;153:189-94

16. Seltzer HS, Allen EW, Herron AL Jr, Brennan MT. Insulin secretion in response to glycemic stimulus: relation of delayed initial release to carbohydrate intolerance in mild diabetes mellitus. J Clin Invest. 1967;46:323-35.

17. Kahn SE, Prigeon RL, McCulloch DK, Boyko EJ, Bergman RN, Schwartz MW, Neifing JL, Ward WK, Beard JC, Palmer JP. Quantification of the relationship between insulin sensitivity and beta-cell function in human subjects: evidence for a hyperbolic function. Diabetes. 1993;42:1663-72.

18. Matsuda M, DeFronzo RA. Insulin sensitivity indices obtained from oral glucose tolerance testing: comparison with the euglycemic insulin clamp. Diabetes Care. 1999;22:1462-70.

19. Freitas P, Santos AC, Carvalho D. Fat mass ratio: an objective tool to define lipodystrophy in HIV-infected patients under antiretroviral therapy. J Clin Densitom. 2010;13:197-203.

20. Ajluni N, Meral R, Neidert AH, et al. Spectrum of disease associated with partial lipodystrophy: lessons from a trial cohort. Clin Endocrinol. 2017:86:698-707.

21. Taylor R. Type 2 diabetes: etiology and reversibility. Diabetes Care. 2013;36:1047-55.

22. Lim EL, Hollingsworth KG, Aribisala BS, Chen MJ, Mathers JC, Taylor R. Reversal of type 2 diabetes: normalization of beta cell function in association with decreased pancreas and liver triacylglycerol. Diabetologia. 2011:54:2506-14

23. Virtue S, Vidal-Puig A. It's not how fat you are, it's what you do with it that counts. PLoS Biol. 2008:6:e237.

24. Scott RA, Fall T, Pasko D, Baker A, Sharp SJ, Arriola L, Balkau B, Barricarte A, Barroso I, Boeing H, Clavel-Chapelon F, Crowe FL, Dekker JM, Fagherazzi
G, Ferranini E, Forouhi NG, Franks PW, Gavrila D, Giedraits V, Grioni S, Groop LC, Kaaks R, Key TJ, Kuhn T, Lotta LA, Nilsson PM, Overvad K, Palli D, Panico S, Quirós JR, Rolandson O, Roswall N, Sacerdote C, Sala N, Sánchez MJ, Schulze MB, Siddig A, Slimani N, Sluijs I, Spiikerman AMW, Tjonneland A, Tumino R, van der A DL, Yaghootkar H, The RISC study group, The EPIC-InterAct consortium, McCarthy MI, Semple RK, Riboli E, Walker M, Ingelsson E, Frayling TM, Savage DB, Langenberg C, Wareham NJ. Common genetic variants highlight the role of insulin resistant and body fat distribution in type 2 diabetes, independent of obesity. Diabetes. 2014;63:4378-87.

25. Yaghootkar H, Scott RA, White CC, Zhang W, Speliotes E, Munroe PB, Ehret GB, Bis JCM, Fox CS, Walker M, Boreki IB, Zhang W, Knowles JW, YergesArmstrong L, Ohisson C, Perry JR, Chambers JC, Kooner JS, Franceschini N, Langenberg C, Hivert MF, Dastani Z, Richards JB, Semple RK, Frayling TM. Genetic evidence for a normal-weight "Metabolically Obese" phenotype linking insulin resistance, hypertension, coronary artery disease and type 2 diabetes. Diabetes. 2014;63:4369-77.

26. Stefan N, Schick F, Hari H. Causes, characteristics and consequences of Metabolically unhealthy normal weight in humans. Cell Metab. 2017;26:292-300

27. Lotta LA, Gulati P, Day FR, Payne F, Ongen H, van de Bunt M, Gaulton KJ, Eicher JD, Sharp SJ, Luan J, Rolfe EDL, Stewart ID, Wheeler E, Willems SM, Adams C, Yaghootkar H, EPIC-InterAct Consortium, Cambridge FPLD1 Consortium, Forouhi NG, Khaw KT, Johnson AD, Semple RK, Frayling T, Perry JR, Dermitzakis E, McCarthy MI, Barroso I, Wareham NJ, Savage DB, Langenberg C, O'Rahilly S, Scott RA. Integrative genomic analysis implicates limited peripheral adipose storage capacity in the pathogenesis of human insulin resistance. Nat Genet. 2017:49:7-26.

28. Akinci B, Onay H, Demir T, Savas-Erdeve Ş, Gen R, Simsir IY, Keskin FE, Erturk MS, Uzum AK, Yaylali GF, Ozdemir NK, AtikT, Ozen S, Yurekli BS, Apaydin T, Altay C, Akinci G, Demir L, Comlekci A, Secil M, Oral EA. Clinical presentations, metabolic abnormalities and end-organ complications in patients with familial partial lipodystrophy. Metab Clin Exp. 2017;72:109-19.

29. Emdin CA, Khera AV, Natarajan P. Genetic association of waist-to-hip ratio with cardiometabolic traits, type 2 diabetes and coronary heart disease. JAMA. 2017;317:626-34.
Ready to submit your research? Choose BMC and benefit from:

- fast, convenient online submission

- thorough peer review by experienced researchers in your field

- rapid publication on acceptance

- support for research data, including large and complex data types

- gold Open Access which fosters wider collaboration and increased citations

- maximum visibility for your research: over $100 \mathrm{M}$ website views per year

At BMC, research is always in progress.

Learn more biomedcentral.com/submissions 